\title{
Rectovaginal Fistulas
}

\author{
Teresa H. deBeche-Adams, M.D. ${ }^{1}$ and Jaime L. Bohl, M.D. ${ }^{2}$
}

\begin{abstract}
Rectovaginal fistulas are abnormal epithelial-lined connections between the rectum and vagina. They can be quite bothersome to both the patient and the surgeon due to their irritating and embarrassing symptoms and high failure rate after repair. An individualized, systematic approach to these fistulas based on their size, location, and etiology provides a more concise treatment plan. Treatment options of medical therapy, advancement flaps, plugs, fistula ligation, and tissue interposition are discussed.
\end{abstract}

KEYWORDS: Rectovaginal fistula, advancement flap, fistulotomy

Objectives: On completion of this article, the reader should be familiar with the diagnosis and management of rectovaginal fistulas.

Rectovaginal fistulas are abnormal epitheliallined connections between the rectum and vagina. They can be quite bothersome to both the patient and the surgeon due to their irritating and embarrassing symptoms and high failure rate after repair.

\section{ETIOLOGY}

Fistulas can be the result of congenital malformations or acquired etiologies. In this article, we will address acquired rectovaginal fistulas.

Rectovaginal fistulas may be caused by childbirth. Prolonged labor with necrosis of the rectovaginal septum or obstetric injury with a third- or fourth-degree perineal tear or episiotomy can lead to rectovaginal fistula. Inadequate repair, breakdown of the repair, or infection can all result in fistula development. Fortunately, rectovaginal fistula from childbirth is less common in developed countries.

Infectious processes within the rectovaginal septum can also result in a rectovaginal fistula. Cryptoglandular anorectal abscesses and Bartholin gland infections may spontaneously drain causing a low rectovaginal fistula. Diverticular disease in the setting of previous hysterectomy is the most common infectious cause of a high fistula. Cases of rectovaginal fistula as a result of tuberculosis and lymphogranuloma venereum have also been reported. ${ }^{1}$

Malignancies may cause rectovaginal fistulas. These are usually seen in the setting of rectal, uterine, cervical, or vaginal malignancies that have significant local extension or have been treated with radiation therapy. Following radiation therapy, the patient may develop proctitis followed by ulceration of the anterior rectal wall. Rectal ulcers then progress to fistula formation around 6 months to 2 years posttherapy. The incidence of rectovaginal fistula increases with highdose radiation and previous hysterectomy. ${ }^{2,3}$ If suspicion for an undiagnosed malignancy is present, biopsy of the fistula should be undertaken.

Operative trauma can result in rectovaginal fistula. Low fistulas may be the result of anorectal and vaginal operations. Low stapled colorectal anastomoses may cause a fistula if the vaginal wall becomes incorporated in the stapler or if an anastomotic leak leads to abscess that then drains into the vagina.
${ }^{1}$ Department of General Surgery, Ochsner Clinic Foundation, New Orleans, Louisiana; ${ }^{2}$ Department of Colon and Rectal Surgery, Ochsner Clinic Foundation, New Orleans, Louisiana.

Address for correspondence and reprint requests: Jaime L. Bohl, M.D., Department of Colon and Rectal Surgery, Ochsner Clinic Foundation, 1514 Jefferson Hwy., New Orleans, LA 70121 (e-mail: jbohl@ochsner.org).
Urology and Gynecology; Guest Editor, David E. Beck, M.D.

Clin Colon Rectal Surg 2010;23:99-103. Copyright (C) 2010 by Thieme Medical Publishers, Inc., 333 Seventh Avenue, New York, NY 10001, USA. Tel: +1(212) 584-4662.

DOI: http://dx.doi.org/10.1055/s-0030-1254296.

ISSN 1531-0043. 
Alternatively, pelvic procedures may result in high rectovaginal fistulas. Hysterectomy following radiation treatment or with unrecognized intraoperative rectal injury may result in fistula development.

Inflammatory bowel disease is another possible culprit. Both ulcerative colitis and Crohn disease can be associated with rectovaginal fistula. Crohn disease is more frequently associated with rectovaginal fistula because it causes transmural inflammation of the rectal wall. The incidence may increase with the severity of a Crohn's flare-up, with one study noting an increase in incidence from $0.2 \%$ with mild flares to $2.1 \%$ with severe attacks. ${ }^{4}$ In Crohn disease, rectovaginal fistulas can precede intestinal symptoms. ${ }^{5}$ Rectovaginal fistula may occur in ulcerative colitis patients after ileo-anal pouch anastomoses with associated anastomotic leak or pelvic abscess.

Other rare causes of fistulas have been reported, including fecal impaction, vaginal dilatation after radiation to the vaginal cuff, viral and bacterial infections in patients with human immunodeficiency virus (HIV), and sexual assault. ${ }^{6-9}$

\section{CLASSIFICATION}

The majority of classification schemes use size, location, and etiology as the criteria to classify rectovaginal fistulas as simple or complex. Classification of the fistula helps determine appropriate therapy.

In using size as a criterion, fistulas less than $2.5 \mathrm{~cm}$ in diameter are considered small; those greater than $2.5 \mathrm{~cm}$ are described as large.

The location of a rectovaginal fistula can be described in relation to the rectum, vagina, and rectovaginal septum. ${ }^{10-13}$ In low fistulas, the rectal defect is at the dentate line with the vaginal opening inside the vaginal fourchette. In high fistulas, the vaginal opening is at the level of the cervix. Middle fistulas are found between the two. Preoperative localization helps determine the appropriate surgical approach. High fistulas are more easily approached through a laparotomy, whereas a perineal approach is usually suitable for the majority of low and middle fistulas.

Simple rectovaginal fistulas consist of small, low fistulas secondary to infection or trauma. These fistulas generally have healthy, well-vascularized surrounding tissue, which can be repaired with local techniques.

Rectovaginal fistulas are considered complex if they are large $(>2.5 \mathrm{~cm})$, high, or caused by inflammatory bowel disease. Recurrent fistulas are also considered complex due to their association with tissue scarring and decreased blood supply. To provide the best chance of successful repair, healthy, well-vascularized tissue needs to be introduced after resection of diseased tissue. In all, complex fistulas require more complicated surgical procedures for repair.

\section{EVALUATION}

Patient symptoms usually depend on the size and location of a rectovaginal fistula. The most frequent symptoms are passage of flatus or liquid stool per vagina. Patients may also complain of a malodorous vaginal discharge and recurrent vaginitis. Questions regarding intestinal symptoms are necessary to rule out inflammatory bowel disease as a cause. Finally, a history of pelvic malignancy should be elicited.

The physical examination is important to locate the fistula and to assess the integrity of surrounding tissue. There may be a palpable depression in the anterior midline of the rectum, or a pit like defect if the fistula is small. These changes may be visible on anoscopy. On vaginal examination, the darker mucosa in the fistula track may be apparent, contrasting with the light vaginal mucosa. There may be visible stool or signs of vaginitis. Probing the tract may be very painful and is therefore not recommended. During the physical examination, an assessment of anal sphincter integrity will assist in surgical planning.

Supplemental studies may be necessary to confirm the presence of a fistula or to determine the extent of underlying disease. Endorectal and transvaginal ultrasounds (Fig. 1) may be used to identify a low fistula tract. $^{14,15}$ Alternatively, a vaginal tampon can be inserted followed by instillation of a methylene blue enema. The tampon is removed after retaining the enema for 15 to 20 minutes. If there is no staining, the diagnosis of rectovaginal fistula is highly unlikely. More proximal fistulas are best diagnosed with vaginography or computed tomography with rectal contrast (Fig. 2). Endoscopy is necessary if inflammatory bowel disease is a

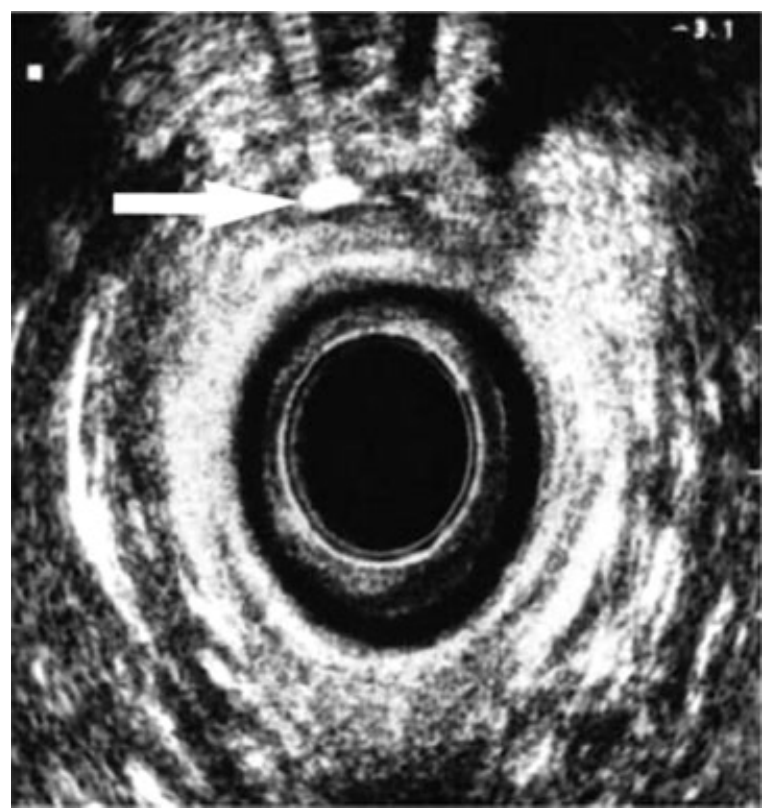

Figure 1 Transrectal ultrasound image demonstrating a fistula highlighted with hydrogen peroxide. 


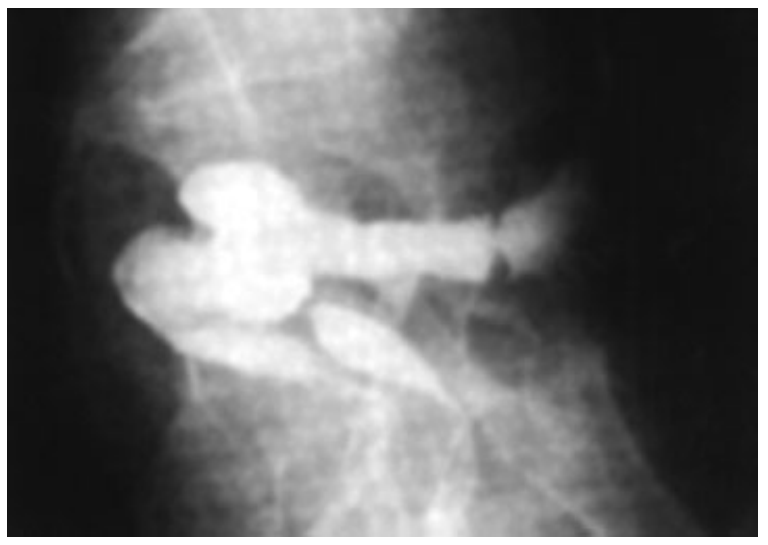

Figure 2 Lateral view of contrast rectal study demonstrating contrast in vagina (rectovaginal fistula).

suspected cause. Examination under anesthesia with biopsies may be necessary in patients with prior irradiation for malignancy. Overall, confirmatory diagnostic studies are only necessary when the rectovaginal fistula eludes identification on physical examination or if the extent of underlying disease is unknown.

All patients require assessment of fecal continence. This may be attainable with a good history; however, some women may have difficulty distinguishing incontinence from fistulous drainage. Incontinence may be caused by the fistula, an underlying disease state, or anal sphincter trauma. Determining the cause of incontinence is important prior to operative intervention for a rectovaginal fistula. ${ }^{16,17}$ Endoanal ultrasound and magnetic resonance imaging (MRI) are quite accurate in identifying a sphincter defect. ${ }^{18}$ Manometry may be used to determine functional sphincter defects in the absence of an anatomic defect. Patients with fistulas arising as a result of an obstetrical injury should be routinely evaluated for anatomic sphincter defects.

\section{TREATMENT}

\section{Conservative Management}

A small subset of patients may respond to medical optimization. This usually includes regulating bowel function and controlling diarrhea. Patients with rectovaginal fistula of obstetric origin may experience fistula healing with this regimen. Unfortunately, most women have persistent symptomatic disease that will not heal without surgical intervention.

\section{General Principles}

Timing is an important part of the surgical decisionmaking process. In the face of infection or inflammation, it is critical to allow resolution prior to repair. Antibiotic therapy or immunosuppressive medications play an important role for surgical preparation. A recommended period of 3 to 6 months for medical therapy has been suggested, but if surrounding tissues appear healthy prior to this, it is reasonable to proceed with surgical repair. Some fistulas may even close spontaneously during this time.

Preoperatively, the patient undergoes mechanical bowel preparation and receives antibiotics. Procedures may be performed under local anesthetic with sedation, but spinal or general anesthesia is typically preferred. Patients are placed in a prone jackknife or left lateral (Simms') position with exposure obtained by taping the buttocks or using a Lone Star retractor. Patients who require abdominal procedures are placed in the lithotomy position.

\section{Simple Rectovaginal Fistulas}

Advancement flaps are the most popular transanal procedure among colorectal surgeons. Many variations exist; however, the general principle remains the same- $\mathrm{ex}^{-}$ cision and closure of the rectal portion of the fistula and coverage with a vascularized mucosal flap on the high pressure side of the fistula. The tract is identified by palpation and probing. The fistula tract is débrided and excised. A flap is created that includes mucosa, submucosa, and muscle placed over reapproximated rectovaginal septum (Fig. 3). ${ }^{19}$ The flap base should be at least 2 to 3 times the width of the apex to ensure adequate vascular supply. Flap mobilization should continue 4 to $5 \mathrm{~cm}$ cephalad to the fistula defect. These principles ensure a tensionless suture line. As described in Table 1 success rates vary from 29 to $100 \% .{ }^{19}$ This wide discrepancy may be explained by differences in technique as well as patient selection. Complications are rare and minor, including fever, urinary tract infection, and spinal headaches.

Two newer approaches that were developed for the treatment of intersphincteric anorectal fistulas have been adopted for treatment of simple rectovaginal fistulas. One approach involves the use of a bioprosthetic fistula plug made from porcine intestinal submucosa (Anal Fistula Plug, Cook Surgical Inc., Bloomington, IN). After management of local sepsis with drainage procedures, a tapered plug is placed through the rectovaginal fistula tract. Excess plug length is excised at both the rectal and vaginal ends. The plug is then secured with 2-0 absorbable suture in a figure-of-eight fashion on the rectal side and the vaginal side left open to drain. Experience with this technique in patients with rectovaginal fistula is limited. ${ }^{20}$ Trials that compare rectal mucosal flap advancement to bioprosthetic plug placement for the treatment of fistula in ano are ongoing. ${ }^{21}$ Smaller studies show that bioprosthetic plugs are more successful in the treatment of simple compared with complicated anorectal fistulas. ${ }^{22}$ Recent modifications to the bioprosthesis to accommodate anatomic features of a 


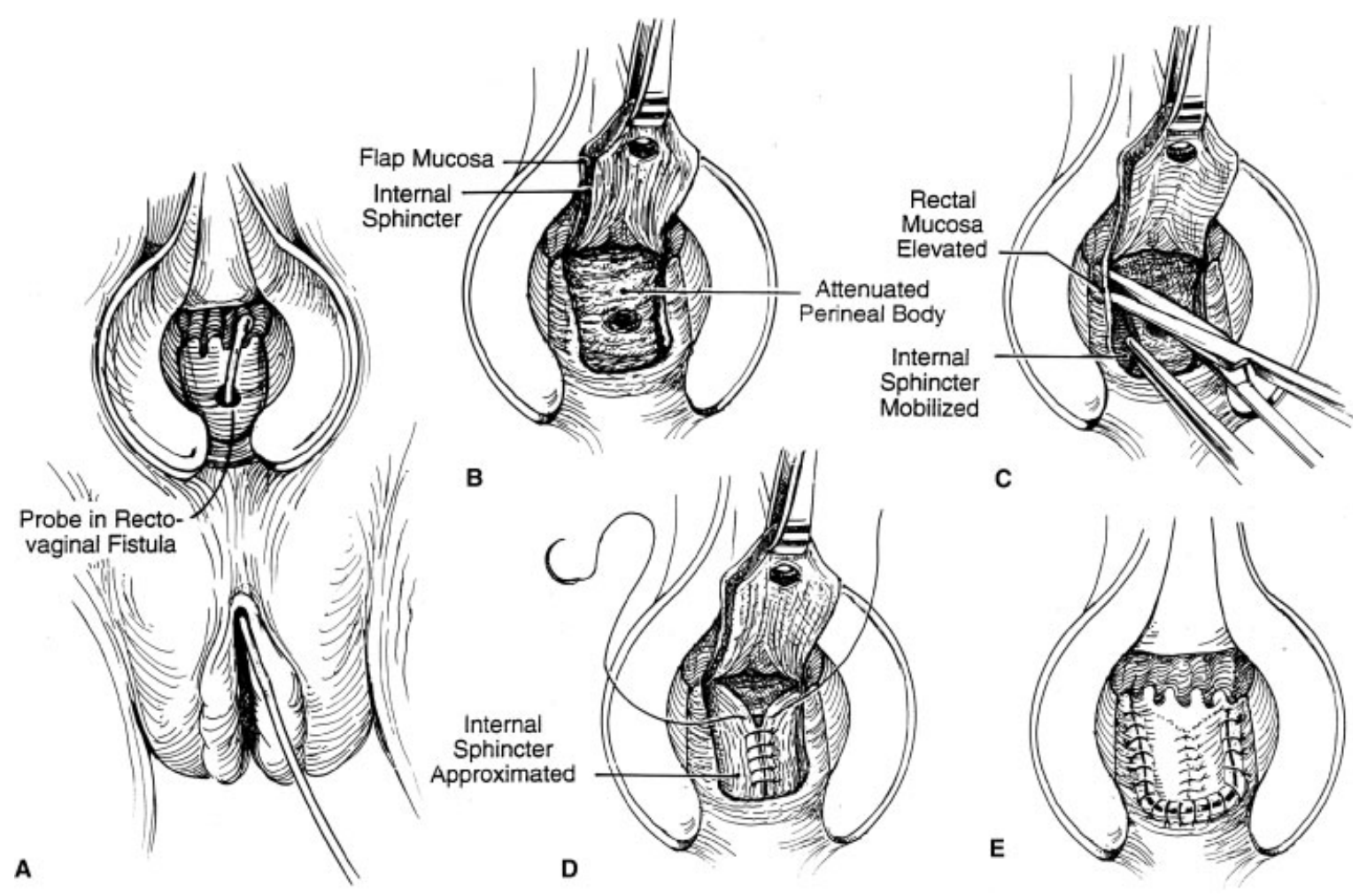

Figure 3 Endorectal advancement flap.

rectovaginal fistula may make this approach more successful $^{23}$; however, additional experience is needed to determine the utility of bioprosthetics in the use of rectovaginal fistula treatment.

A second recently popularized surgical treatment for fistula in ano has been adopted to treat rectovaginal fistula. The procedure which is coined LIFT (ligation of intersphincteric fistula tract), involves dissection in a bloodless plane between the internal and external anal sphincters beyond the fistula tract. The tract is then ligated and closed on both the rectal and perineal side. The intersphincteric dissection is then closed at the skin. High success rates after LIFT treatment of fistula in ano are encouraging (60-94\%), ${ }^{24,25}$ but experience with LIFT treatment of rectovaginal fistula is limited. The bioprosthetic plug and LIFT repair for both rectovaginal

Table 1 Outcome of Transanal Flap Advancements

\begin{tabular}{llll}
\hline Author & Year & $\begin{array}{l}\text { Number } \\
\text { of Patients }\end{array}$ & $\begin{array}{l}\text { Success } \\
\text { (\%) }\end{array}$ \\
\hline Mengert and Fish & 1955 & 9 & 100 \\
Belt and Belt & 1969 & 8 & 100 \\
Russell and Gallgher & 1977 & 21 & 78 \\
Hilsabeck & 1980 & 9 & 100 \\
Hoexter et al & 1985 & 35 & 100 \\
Jones et al & 1987 & 12 & 75 \\
Stern and Drezink & 1987 & 8 & 87.5 \\
Lowry and Goldberg & 1991 & 85 & 78 \\
Wise et al & 1991 & 34 & 96 \\
\hline
\end{tabular}

fistula and fistula in ano are attractive because they allow the surgeon to avoid anal sphincter muscle division. Long-term impact on fecal continence in patients with other risk factors for incontinence remains a high priority for both patient and surgeon.

\section{Complex Rectovaginal Fistulas}

Due to the abnormal surrounding tissue, high location, and large size of complex fistulas, attempts at local repair are fraught with failure. The unhealthy tissue must be removed and new, viable tissue introduced to correct the problem. This is usually accomplished with abdominal resection procedures or tissue interposition techniques. Low anterior resection is one option. This allows for resection of diseased bowel and colon anastomosis below the level of the fistula. Abdominoperineal resection or pelvic exenteration may be necessary in the presence of extensive malignancy. Rectovaginal fistula repair should be postponed in the face of inflammation. This is especially important for postradiation fistulas and those caused by inflammatory bowel disease. Initially, diverting loop colostomy or ileostomy with concomitant medical therapy allows for resolution of inflammation. A subsequent rectovaginal fistula repair can then be performed with greater success. Tissue interposition through a perineal approach may be appropriate for high-risk surgical patients. Advantages include avoidance of a highrisk abdominal procedure; however, the disadvantage is that damaged tissue may be left in the surgical field. 
Options for tissue interposition using a perineal approach include a labial fat pad, bulbocavernous muscle, and pedicled muscle flaps (rectus, sartorius, and gluteal muscles), as well as bioprosthetic materials. The actual surgical approach in patients with complex rectovaginal fistulas should be individualized to each patient.

Management of rectovaginal fistulas in patients with Crohn disease has improved secondary to advances in medical therapy. Control of inflammation has allowed some patients to be treated with local repair techniques. Advancement flap success rates have recently approached 60 to $70 \% .^{26,27}$ The failure rate is still considered high, and nearly 50\% may need additional surgical treatment. Patients with refractory proctitis, anal stricture, and rectovaginal fistula require permanent ostomy placement, proctectomy, and fistula repair. Symptomatic ulcerative colitis that has failed medical management is treated with total proctocolectomy. Complicated ulcerative colitis with associated rectovaginal fistula may also be treated in this manner. Restoration of continence can be performed with ileo-anal pouch construction, although the pouchto-sphincter anastomosis must be separated from a rectovaginal fistula repair.

\section{CONCLUSION}

Rectovaginal fistulas have long been a very agonizing, symptomatic disease plaguing both the patient and surgeon. An individualized, systematic approach to these fistulas based on their size, location, and etiology provides a more concise treatment plan for their resolution, which is possible with correct technique.

\section{REFERENCES}

1. Greenwald JC, Hoexter B. Repair of rectovaginal fistulas. Surg Gynecol Obstet 1978;146(3):443-445

2. Perez CA, Breaux S, Bedwinek JM, et al. Radiation therapy alone in the treatment of carcinoma of the uterine cervix. II. Analysis of complications. Cancer 1984;54(2):235-246

3. Boronow RC. Repair of the radiation-induced vaginal fistula utilizing the Martius technique. World J Surg 1986;10(2): 237-248

4. de Dombal FT, Watts JM, Watkinson G, Goligher JC. Incidence and management of anorectal abscess, fistula and fissure, in patients with ulcerative colitis. Dis Colon Rectum 1966;9(3):201-206

5. Sher ME, Bauer JJ, Gelernt I. Surgical repair of rectovaginal fistulas in patients with Crohn's disease: transvaginal approach. Dis Colon Rectum 1991;34(8):641-648

6. Schwartz J, Rabinowitz H, Rozenfeld V, Leibovitz A, Stelian J, Habot B. Rectovaginal fistula associated with fecal impaction. J Am Geriatr Soc 1992;40(6):641

7. Hoffman MS, Wakeley KE, Cardosi RJ. Risks of rigid dilation for a radiated vaginal cuff: two related rectovaginal fistulas. Obstet Gynecol 2003;101(5 Pt 2):1125-1126
8. Sharland M, Peake J, Davies EG. Pseudomonal rectovaginal abscesses in HIV infection. Arch Dis Child 1995;72(3):275

9. Parra JM, Kellogg ND. Repair of a recto-vaginal fistula as a result of sexual assault. Semin Perioper Nurs 1995;4(2): $140-145$

10. Corman ML. Rectovaginal fistulas. In: Colon and Rectal Surgery. 2 ed. Philadelphia: JB Lippincott Co.; 1989

11. Bentley RJ. Abdominal repair of high rectovaginal fistula. J Obstet Gynecol Br Commonw 80(4):364-367

12. Daniels BT. Rectovaginal Fistula: A Clinical and Pathological Study [master's thesis]. Minneapolis: University of Minnesota Graduate School; 1949

13. Rosenshein NB, Genadry RR, Woodruff JD. An anatomic classification of rectovaginal septal defects. Am J Obstet Gynecol 1980;137:439-442

14. Stoker J, Rociu E, Schouten WR, Laméris JS. Anovaginal and rectovaginal fistulas: endoluminal sonography versus endoluminal MR imaging. AJR Am J Roentgenol 2002; 178(3):737-741

15. Alexander AA, Liu JB, Merton DA, Nagle DA. Fecal incontinence: transvaginal US evaluation of anatomic causes. Radiology 1996;199(2):529-532

16. Tsang CB, Madoff RD, Wong WD, et al. Anal sphincter integrity and function influences outcome in rectovaginal fistula repair. Dis Colon Rectum 1998;41(9):11411146

17. Khanduja KS, Yamashita HJ, Wise WE Jr, Aguilar PS, Hartmann RF. Delayed repair of obstetric injuries of the anorectum and vagina. A stratified surgical approach. Dis Colon Rectum 1994;37(4):344-349

18. Stoker J, Rociu E, Schouten WR, Laméris JS. Anovaginal and rectovaginal fistulas: endoluminal sonography versus endoluminal MR imaging. AJR Am J Roentgenol 2002; 178(3):737-741

19. Stone JM, Goldberg SM. The endorectal advancement flap procedure. Int J Colorectal Dis 1990;5(4):232-235

20. Ellis CN. Outcomes after repair of rectovaginal fistulas using bioprosthetics. Dis Colon Rectum 2008;51(7):1084-1088

21. van Koperen PJ, Bemeiman WA, Bossuyt PM, et al. The anal fistula plug versus the mucosal advancement flap for the treatment of anorectal fistula (PLUG trial). BMC Surg 2008;23(8):11

22. Ky AJ, Sylla P, Steinhagen R, Steinhagen E, Khaitov S, Ly EK. Collagen fistula plug for the treatment of anal fistulas. Dis Colon Rectum 2008;51(6):838-843

23. Gonsalves S, Sagar P, Lengyel J, Morrison C, Dunham R. Assessment of the efficacy of the rectovaginal button fistula plug for the treatment of ileal pouch-vaginal and rectovaginal fistulas. Dis Colon Rectum 2009;52(11):18771881

24. Rojanasakul A, Pattanaarun J, Sahakitrungruang C, Tantiphlachiva K. Total anal sphincter saving technique for fistula-in-ano; the ligation of intersphincteric fistula tract. J Med Assoc Thai 2007;90(3):581-586

25. Bleier JI, Moloo H, Goldberg SM. Ligation of intersphincteric fistula tract: an effective technique for complex fistulae. Dis Colon Rectum 2010;53(1):43-46

26. Radcliffe AG, Ritchie JK, Hawley PR, Lennard-Jones JE, Northover JMA. Anovaginal and rectovaginal fistulas in Crohn's disease. Dis Colon Rectum 1988;31(2):94-99

27. Sher ME, Bauer JJ, Gelernt I. Surgical repair of rectovaginal fistulas in patients with Crohn's disease: transvaginal approach. Dis Colon Rectum 1991;34(8):641-648 